\title{
GUIA PARA O PROCESSO DE AJUDA INTERPESSOAL DE ENFERMAGEM AO FAMILIAR DO PACIENTE CRÍTICO
}

\author{
GUIDE FOR INTERPERSONAL PROCESS OF HELP IN NURSING \\ TO RELATIVES OF THE CRITICAL PATIENT
}

\section{GUÍA PARA EL PROCESO DE AYUDA INTERPERSONAL DE ENFERMERÍA AL FAMILIAR DEL PACIENTE CRÍTICO}

\author{
Adriana Braitt Lima \\ Darci de Oliveira Santa Rosa ${ }^{* *}$
}

\begin{abstract}
RESUMO
Fundamentando-se no referencial de Viktor Frankl, propõe-se um guia sobre o processo de ajuda interpessoal entre a enfermeira e o familiar do paciente em estado crítico. Trata-se de uma estratégia sustentada em uma perspectiva humanista, existencial e personalista para despertar, no profissional enfermeiro, sua atuação ética, consciente e responsável pelo cuidado. O tema surgiu da tríade trágica: sofrimento, culpa e morte, vivenciada pelo familiar do paciente em estado crítico hospitalizado em uma Unidade de Terapia Intensiva (UTI), de um hospital geral e privado da cidade de Salvador, Brasil. Considerando-se que do trágico emerge o otimismo e este possibilita a resiliência para direcionar o cuidado do enfermeiro até o familiar do paciente em estado crítico, a proposta do guia possui quatro etapas: diagnóstico triádico, planejamento de ajuda, aplicação das estratégias de ajuda e avaliação do processo de ajuda. Com esta ferramenta, espera-se apoiar a transformação da tríade trágica, ou seja, transformar o sofrimento em atitude, a culpa em reflexões para a mudança e a possibilidade de morte, em ações responsáveis.
\end{abstract}

Palavras chave: Processo de ajuda interpessoal, papel da enfermeira, relações profissional-família, Unidade de Terapia Intensiva.

\begin{abstract}
Based on Viktor Frankl's logotherapy, a guide on the process of interpersonal help between the nurse and the relatives of the critically-ill patient is proposed. This is a strategy based on a humanist, existential and personalistic perspective, to awake, in the professional nurse, their ethical, conscious and responsible action towards caring. The theme arose from Frankl's tragic triad: suffering, guilt and death, experienced by the relative of the critically-ill patient treated in an Intensive Care Unit (ICU), of a general and private hospital in the city of Salvador, Brazil. Considering the fact that from tragic events optimism emerges and it generates resilience to direct the care of the nurse towards the relatives of the patient in critical condition, the proposed guide has four stages: triadic diagnosis, aid planning, application of the aid strategies and evaluation of the aid process. With this tool it is expected to support the transformation of the tragic triad, that is, to transform suffering into attitude, guilt into reflections for change, and the possibility of death into responsible actions.
\end{abstract}

Key words: Interpersonal help process, Nurse’s role, Professional-family relations, Intensive Care Unit.

\footnotetext{
* Doutora em Enfermagem. Professora Adjunta da Universidade Estadual de Feira de Santana (UEFS), Brasil. Email: enfbraitt@gmail.com

** Doutora em Enfermagem. Professora do Programa de Pós-Graduação em Enfermagem e Saúde da Universidade Federal da Bahia UFBA, Brasil. Email: darcisantarosa@gmail.com
} 


\section{RESUMEN}

Fundamentada en el referencial de Víctor Frankl se propone una guía sobre el proceso de ayuda interpersonal de enfermería hacia el familiar del paciente crítico. Se trata de una estratégia sustentada en una perspectiva humanista, existencial y personalista para despertar, en el profesional de enfermería, su actuar ético, consciente y responsable por el cuidado. El tema surge de la tríada trágica -sufrimiento, culpa y muerte- vivenciada por el familiar del paciente crítico hospitalizado en una Unidad de Cuidados Intensivos (UCI), de un hospital general y privado de la ciudad de Salvador, Brasil. Considerando que de lo trágico emerge el optimismo que hace posible la resiliencia para iluminar el cuidado de enfermería hacia el familiar del paciente crítico, la guía propuesta posee 4 etapas: diagnóstico triádico, planificación de ayuda, aplicación de estrategias de ayuda y evaluación del proceso de ayuda. Con esta herramienta se espera apoyar la transformación de la tríada trágica, es decir, el sufrimiento en actitud, la culpa en reflexiones para el cambio y la posibilidad de muerte en acciones responsables.

Palabras clave: Proceso de ayuda interpersonal, rol de la enfermera, relaciones profesional-familia, Unidades de Cuidados Intensivos.

Fecha recepción: 04/02/15 Fecha aceptación: 15/12/16

\section{INTRODUÇÃO}

O processo de ajuda em enfermagem consiste numa orientação para a atenção de cuidado ao ser humano. Constitui-se de comportamentos e ações que possibilitam o encontro entre pessoa-pessoa para o estabelecimento de um laço de respeito e confiança do ser cuidado para o ser que cuida, favorecido pela intenção em ajudar com comiseração, benevolência, estima, amabilidade, atenção, solidariedade e motivação (1). O cuidar é um ato de ajuda que envolve tanto zelo, atenção, proteção, preocupação e atitudes quanto sentimentos e comportamentos que fortalecem as circunstâncias do vivido, pela necessidade explicita ou antecipada de aliviar uma vida ou condição humana $(2,3)$. Nas circunstâncias de vulnerabilidade pelo sofrimento e incapacidades, a ajuda ocupa o seu ponto máximo, como um apoio em que a pessoa que cuida precisa estar sensibilizada e habilitada para buscar a restauração afora da dimensão física e do objetivismo para compreender o ser cuidado em sua singularidade (4). É nas situações de finitude da vida que surgem as maiores dificuldades, pela necessidade de dedicar atenção para o conforto e pela consciência da condição do paciente, da necessidade do cuidado individualizado e do apoio aos familiares no processo de luto (5).

Essas dificuldades estão presentes na UTI, cenário do hospital com tratamentos de risco, emoções, falta de esperança de cura e trabalho estressante pela concentração de pacientes de alta complexidade com possibilidade de morte (6). Os familiares desses pacientes podem apresentar sentimentos de desconfiança, insegurança e sofrimento quer seja durante a visita beira leito, quer seja na sala de espera da UTI. Para aguçar a visão de mundo na busca da compreensão do familiar no ambiente da UTI, faz-se necessário somar a essa meta o compromisso moral, motivado para agir com solidariedade pela vontade de ser humano (7). A percepção de um significado para ajudar na prática do enfermeiro, orientado por um referencial teórico-filosófico seria uma bússola para essa trilha, com possibilidade de resiliência para o familiar e paciente (8). Em outras palavras, seria uma condição de modificar uma situação de sofrimento em crescimento e superação pela vontade de sentido em dizer sim em cada situação vivida, apesar de tudo (9).

Nessa perspectiva, a proposta deste artigo é apresentar um guia sobre o processo de 
ajuda interpessoal de enfermagem ao familiar do paciente crítico, com base na tríade trágica -sofrimento, culpa e morte- vivenciada pelo familiar do paciente crítico hospitalizado em uma Unidade de Terapia Intensiva (UTI), de um hospital geral e privado na cidade de Salvador, Brasil.

A guia emerge como um novo espaço de atuação do enfermeiro para dar apoio a esse ser que sofre na esperança de mudanças devido à condição do seu familiar que se encontra em estado crítico. Também pode vir a ser uma estratégia de intervenção no cuidado de enfermagem, por tratar-se do sofrimento e este ser um fenômeno existencial.

\section{O referencial Frankliano na vivência do familiar do paciente crítico}

O referencial teórico-filosófico do guia para o processo de ajuda interpersonal de enfermagem ao familiar do paciente crítico fundamentou-se no Processo de Enfermagem da Teoria das Necessidades Humanas Básicas e na Análise Existencial Frankliana (10-12). A Análise Existencial Frankliana é pautada nas experiências valorativas do ser humano perante o que poderá "vir a ser" no percurso da sua vida, uma forma específica de compreender o ser-familiar como pessoa facultativa, ilimitada de possibilidades perante o sofrimento da situação do seu familiar crítico (13). Ao se apreender o ser-familiar, esperase transformar a tríade trágica-sofrimento, culpa e morte- em otimismo trágico, isto é [...] um otimismo diante da tragédia e tendo em vista o potencial humano que, nos seus methores aspectos, sempre permite: 1. transformar o sofrimento numa conquista e numa realização humana; 2. extrair da culpa a oportunidade de mudar a si mesmo para melhor; 3. fazer da transitoriedade da vida um incentivo para realizar ações responsáveis (14).

É possível, para o familiar do paciente crítico, encontrar sentido no sofrimento, ao transformá-lo num desafio que precisa ser alcançado, por meio de uma atitude que emerge como uma força, pela fé em Deus que se revela; crença em um milagre de Deus para a cura; crença na religião como salvação do seu familiar e nas práticas religiosas como busca de paz; e esperança na medicina para reverter à situação do familiar internado na UTI (10).

Mesmo com sofrimento acompanhado por sentimentos de dor, perda e angústia, os familiares mantêm a esperança diante da situação do seu ente querido na UTI, como uma força que levaria a um pensamento positivo, que pode ser por meio de crenças religiosas e/ou palavras de carinho e perdão (6).

Do sentimento de culpa do familiar do paciente crítico, aparece a possibilidade de reflexões para a mudança pelo pensamento do que poderia ter feito para evitar a doença do seu enfermo crítico, pela preocupação de deixar seu familiar sozinho no leito da UTI considerando uma traição, por considerar a situação concreta do seu familiar um castigo divino e autopunição ao ver o seu familiar na UTI e ele próprio com saúde (10). São sentimentos pessoais que podem emergir do sentimento de culpa, e não cabe ao enfermeiro julgar os comportamentos do familiar, resultantes desses processos, porque a relação com seu enfermo foi vivida apenas por ele de modo particular. A culpa do familiar na UTI pode ser devido à sensação de impotência para intervir no contexto em que se encontra o seu enfermo, o que leva a impossibilidade de manter as atividades e rotinas diárias, são alterações que a hospitalização e a doença trazem ao seu cotidiano (15).

Diante da eminência de morte, emergem reflexões sobre a compreensão do tema "morte" e lembranças de outras mortes, comparando-as com o sofrimento do seu enfermo, como ainda, ações de responsabilidade: de colaborar com a equipe de profissionais no que for necessário, de criar sobrinhos e filhos, de estudar e trabalhar; significando reações de comprometimento com a vida perante a perda do seu ente e que não estará presente nessas ações no futuro (10). 


\section{MÉTODO}

A experiência dos familiares dos pacientes críticos foi considerada para o desenvolvimento do guia para o processo de ajuda interpessoal ao familiar do paciente crítico. Para isso, os achados do estudo O Sentido de Vida do Familiar do Paciente Crítico, projeto aprovado pelo Conselho de Ética da instituição, conforme o registro CM-007/01 e a Resolução 196/96 das Diretrizes para Pesquisa com Seres Humanos no Brasil, serviram de norte pelos depoimentos originais revelados e compreendidos.

O estudo foi realizado na UTI de hospital geral e privado na cidade de Salvador-Brasil com seis familiares de pacientes críticos no total de uma população de 10 entrevistados, escolhidos com base nos seguintes critérios de inclusão: estar esclarecido acerca do diagnóstico e prognóstico do seu familiar; ter o seu familiar classificado como grave ou crítico; ser o familiar que mora com o paciente; ser o familiar mais presente no período de internação; concordar livremente em participar do estudo e assinar o termo de consentimento livre e esclarecido.

Optou-se pela abordagem qualitativa quanto à possibilidade de apreensões possíveis de como esse fenômeno, o sentido de vida do familiar do paciente crítico, se revelaria. Para tanto, os participantes foram abordados por meio da entrevista semi-estruturada utilizando-se o gravador com questões de aproximação: você sabe o que está acontecendo com seu familiar? Como era sua vida antes do seu familiar adoecer? E, a questão norteadora: como está sua vida neste momento? (16).

Produção dos dados foi por meio da análise de conteúdo de Bardin (17) que consiste num método de categorização que organiza a constituição de elementos de significação da mensagem expressada. Após a leitura dos depoimentos, selecionou-se unidades de registros (frases, sentimentos, expressões), que ao serem agrupadas levando-se em conta a frequência ou ausência de significados conforme o objeto de estudo, originaram as unidades de contexto, subcategorias e categorias. A categorização possibilitou a descrição e compreensão dos significados com o emergir das categorias: o vazio existencial, a morte, a culpa, o sofrimento, o sentido de vida e a assistência ao familiar crítico.

Considerando essas categorias, as autoras desse estudo, enfermeiras com experiência em unidade de terapia intensiva, elaboraram um guia para o processo de ajuda interpessoal de enfermagem ao familiar do paciente crítico com o intuito de possibilitar o cuidado ao familiar de modo padronizado, visando auxílio humano e personalizado com significado pleno na relação entre o enfermeiro e familiar. Não se trata de um estudo para se investigar quantitativamente a evidência desse conteúdo, mas um caminho de ajuda interpessoal de enfermagem aos familiares pelo compreendido do sentido de vida dos familiares frente à tríade trágica, subsidiado pelo conhecimento teórico-filosófico da Análise Existencial Frankliana.

\section{RESULTADOS}

O processo de ajuda interpessoal ao familiar do paciente crítico tem ações inter-relacionadas e sistematizadas centradas no cuidado ao ser humano (11) e constituído pelas etapas: diagnóstico triádico, planejamento de ajuda de enfermagem, implantação de estratégias de ajuda e avaliação do processo de ajuda.

Diagnóstico triádico. Representa o primeiro passo do processo de ajuda do familiar do paciente crítico e visa à obtenção de dados para conhecê-lo em sua existencialidade. Nesse sentido, constitui um auxílio à reflexão sobre a aquisição e o domínio dos conhecimentos e habilidades necessários ao cuidado, para identificar as fragilidades e as possibilidades 
de lidar com o familiar do paciente crítico.

É no diagnóstico que se identificará a intensidade e extensões das necessidades psicofisiológicas, psicossociais e psicoespirituais do familiar do paciente crítico e se perceberá a sua situação existencial (11). Relacionando essas necessidades com a tríade trágica, verificamos a presença de necessidades afetadas pela presença na culpa de sentimentos de insegurança e impotência; na possibilidade de morte pelo luto, perda antecipada e terminalidade; no sofrimento pela falta de fé, dor, tristeza, angústia, vazio, palpitações e tremores, entre outros (10).

O profissional enfermeiro, devido a sua maior disponibilidade e acessibilidade é aquele que possui mais capacidade para identificar e compreender as necessidades e dificuldades da pessoa hospitalizada e daqueles que o acompanham $(5,18)$. Inicialmente, o enfermeiro realizará a entrevista, considerando-a como um encontro existencial. Esse acontecimento exigirá o reconhecimento de que precisará preocupar-se com o seu olhar, escuta e fala, pois a sua maneira de "ser" na entrevista pode interferir no seu expressar durante o contato com o familiar (11). Daí a preocupação do enfermeiro reconhecer que a entrevista precisa de características rigorosas para que o familiar do paciente crítico revele-se com uma identidade própria. $\mathrm{O}$ enfermeiro estará livre de qualquer idéia ou pressuposto sobre o que se revelará. Então, o encontro existencial desafia o entrevistador a "sacudir" o seu eu, pela reflexão que faz de si mesmo de como se apresentará ao outro.

Com esta preocupação, para se chegar ao diagnóstico triádico, a atitude filosófica e a intencionalidade do enfermeiro subsidiará a mudança da tríade trágica em otimismo trágico. A atitude filosófica é a assunção de uma posição filosófica a respeito da pessoa, do valor, do conhecimento e da realidade (16). Ela se manifesta pelo olhar compreensivo, buscando não julgar mas entender, a partir da apreciação no modo de ser da pessoa, para a busca do conhecimento mais íntimo desta.
O colocar-se no lugar do outro, a percepção dos sentimentos, do valor e do prazer com a experiência do ser humano são um sentido para a abertura à realidade da pessoa que precisa de atenção. A intencionalidade é um pensamento voluntário, consciente e com sentido em cada atitude, permeado pela visão de buscar possibilidades para aquilo que se poderia ser, não sendo valorativo à solução dos problemas a partir das suas causas, mas, da aceitação desses sem questionamento, tirando proveito da tentativa de perceber o melhor deles (19). Após a entrevista e de posse da análise das informações obtidas, o enfermeiro vai para o passo seguinte, que é o da identificação de configurações de sentido, ou seja, das condições que justifiquem o por$q u e ̂$ e o para quê da existência do familiar do paciente crítico naquele momento, ajudando-o a encontrar o sentido de seu sofrimento (porquê) e a compreender a razão da sua existência (o para quê ou para quem viver).

Planejamento de ajuda de enfermagem ao familiar do paciente crítico. De posse do diagnóstico, o enfermeiro fará o planejamento de ajuda de enfermagem ao familiar do paciente crítico, a partir da compreensão da concretude vivida pelo familiar, estabelecendo estratégias para que as necessidades psicobiológicas, psicossociais e psicoespirituais identificadas sejam atendidas, como exemplo: promoção de sentimentos positivos, despertando-o para que ele seja capaz de preencher o vazio no qual se encontra; apresentação de mensagens de otimismo, esperança, fé e amor; estímulo à transformação da tríade trágica em otimismo trágico; apresentação de opções de valores criativos, vivenciais e atitudinais. O planejamento possibilitará a compreensão das preocupações, desventuras e temores ao qual o familiar do paciente crítico está exposto, ao mesmo tempo que será um desafio para o enfrentamento da situação do seu enfermo crítico.

Implantação de estratégias de ajuda. O ser 
humano, ao conviver com uma situação de sofrimento, tem o destino a lhe exigir uma escolha, como uma resposta pessoal que o mobilizará para o enfrentamento de um desafio. Permitir que o ser humano perceba possibilidades concretas para ordenar a sua vida no sofrimento, dentro de um contexto positivo, é o encontro de atitude para um sentido na tragicidade, em outras palavras, seria mostrar-lhe o porquê, e o mais ele próprio encontrará o caminho (20). A implantação das estratégias de ajuda consiste na prática do planejamento com a execução das estratégias de ajuda, constituído de um roteiro diário das necessidades psicofisiológicas, psicossociais e psicoespirituais identificadas no diagnóstico com as intervenções sob coordenação do enfermeiro (11). O enfermeiro pode ajudar ao familiar ao encontro de um caminho para possibilidades de sentido para atender as suas necessidades afetadas a partir da implementação de estratégias de apoio no enfrentamento da tríade trágica.

Avaliação do processo. A avaliação de enfermagem, também nomeada de evolução de enfermagem, consiste no relato diário das mudanças ou respostas sucessivas que ocorrem no ser humano sob o cuidado prestado (11). O atendimento de enfermagem ao familiar do paciente crítico deve ser avaliado pelo enfermeiro em todos os momentos, tendo em vista que as etapas do processo, com as estratégias de ajuda de enfermagem, não são estáticas, e podem ser ajustadas a depender da situação particular vivenciada pelo familiar na relação ou não com o paciente crítico, com os profissionais da equipe de saúde e/ou percebida/vivida pelo enfermeiro.

\section{GUIA PARA O PROCESSO DE AJUDA INTERPESSOAL DE ENFERMAGEM AO FAMILIAR DO PACIENTE CRÍTICO}

Quadro 1. Síntese das ações para a elaboração do diagnóstico triádico e plano de ajuda.

LEVANTAMENTO DE DADOS PARA O DIAGNÓSTICO DA NECESSIDADE DE AJUDA

Efetua a atitude filosófica: o enfermeiro considera o familiar como uma pessoa singular e original, compreendendo a vivência diante da tríade trágica.

Considera a existencialidade do familiar: o enfermeiro considera sua maneira de se expressar diante de uma situação concreta em situações que envolvem a Tríade trágica.

Identifica a intencionalidade: o enfermeiro ajuda a transformar a tríade trágica em otimismo trágico, buscando um sentido para a vida do familiar.

Realização do levantamento dos dados no prontuário.

Aproximação e observação do comportamento do paciente crítico, sua postura no leito, comportamentos evidenciados, uso de equipamentos e medicamentos.

Obtenção de informações da enfermagem quanto à evolução, ao prognóstico e à relação do paciente com a família durante as visitas.

Identificação: nome, idade, religião, ocupação e diagnóstico médico. 
APROXIMAÇÃO DO FAMILIAR

Apresentação do profissional ao familiar do paciente crítico.

Explicação da finalidade da sua entrevista.

Agendamento de um momento para entrevista conforme disponibilidade do familiar e o seu consentimento para ser entrevistado.

Identificação, durante a entrevista, da situação biológica, psicológica, e espiritual do familiar do paciente crítico através de expressões que revelem valores vivenciais, criativos e atitudinais, diante de: sofrimento, culpa, morte, vazio existencial, intencionalidade, sentido e consciência.

\section{IDENTIFICAÇÃO DAS CONFIGURAÇÕES DE SENTIDO}

Identificação das configurações de sentido ou seja, condições que lhe justifiquem o por quê e o para quê da existência do familiar do paciente crítico naquele momento, ajudando-o a encontrar o sentido do seu sofrimento (por quê) e a compreender a razão da sua existência (o para quê ou para quem viver).

\section{PLANO DE AJUDA}

Promover sentimentos positivos, despertando-o para que ele seja capaz de preencher o vazio no qual se encontra, através de mensagens de otimismo, esperança, fé e amor.

Ajudar ao familiar do paciente crítico, estimulando-o à transformação da tríade trágica em otimismo trágico, fundamentada nos valores criativos, vivenciais e atitudinais.

A construção do diagnóstico triádico e plano de ajuda farão o enfermeiro apreender a singularidade do ser familiar do paciente crítico, como um enlace do vivido que será, atentivamente, percebido na medida em que o familiar se revelar abrindo caminhos para possibilidades de ajuda, especificamente, a transformação da tríade trágica em otimismo trágico. $\mathrm{O}$ descortinar dessas potencialidades seriam valores vivenciais, ou seja, caminhos de sentidos para a sua própria existência (12).

As interrogações, como por que viver?
Para quem é importante viver? Para que viver? podem ser entendidas por meio das configurações de sentido nas falas dos familiares dos pacientes críticos. As configurações de sentido são resultado da vontade de sentido ou desejo de sentido ou motivação primária, definida como o interesse do ser humano pelo significado da sua vida, e surge independente das dificuldades da vida, como uma busca para o encontro de sentimentos positivos (13).

Quadro 2. Implementação de estratégias de ajuda.

\section{MOTIVAÇÃO DO FAMILIAR DO PACIENTE CRÍTICO ÀS REALIZAÇÕES, TENDO CONFIANÇA NOS CONTEÚDOS DE SENTIDO}

Estimular a confiança do familiar do paciente crítico em algo que lhe seja significativo, a fim de que tenha força para lutar contra o pessimismo. Esse algo pode ser: fé em deus, fé na cura, amor por um filho, esperança na medicina, dentre outros.

Mostrar ao familiar do paciente crítico que ele precisa confiar previamente numa possibilidade de cura do seu familiar para ter força. Mesmo que o prognóstico seja sombrio, existem sempre oportunidades para o enriquecimento interior, que em qualquer momento pode emergir. 
Continuação Quadro 2.

Para incentivá-los a acreditar nas possibilidades de melhora do seu paciente crítico. Descobrir qual é a crença e a sua fé na vida do familiar.

Demonstrar, através de palavras esclarecedoras e amigas que, se ele acreditar que nada tem sentido, a sua motivação para suas manifestações espirituais e conteúdos de sentido, diante da vida, não aparecerão.

Não esconder do familiar do paciente crítico, pois ele precisa estar consciente da realidade concreta do seu familiar na UTI e ter confiança na palavra dos que acompanham o seu doente.

Despertar no familiar do paciente crítico o pensamento de que a sua presença na UTI tem significado.

Estar atenta ao risco da perda de confiança, e evitar que isso ocorra pois levaria o familiar a experimentar o vazio existencial, expresso em situações de falta de fé e de esperança, diminuição da percepção positiva, angústia, tristeza, medo, indiferença e tédio.

Despertar a sensibilidade para saber ouvir, calar e falar, integrando alegrias e tristezas.

Transformar a hostilidade do familiar em atitude criativa, compreendendo e perdoando seu comportamento, o que o levará à reflexão e ao emergir de atitudes e expressões de outros valores.

Despertar no familiar a consciência de que, apesar do sofrimento, ele pode transformar a sua realidade concreta, para que tenha sentido, assumindo uma atitude melhor e mais digna diante do inevitável, o que acontece ao se motivar a busca de um para quê viver, que pode ser por alguém que ele cria ou por um trabalho.

O fundamento para esse agir do enfermeiro é a convicção de que o familiar do paciente crítico, tendo fé em algo e se preocupando em fazer algo positivo na situação vivenciada, estará caminhando para a expressão de valores de atitudes.

Quadro 3. Implementação de estratégias de ajuda.

ESTIMULAR O FAMILIAR DO PACIENTE CRÍTICO À PERCEPÇÃO DA AMPLIAÇÃO DE CONTEÚDOS DE SENTIDO

Fortalecer o familiar para que alcance certo nível de equilíbrio, apesar de todo o sofrimento.

Consolar o familiar através de um sofrimento compartilhado.

Auxiliá-lo na percepção dos conteúdos de sentido, para o que se faz necessário que ele queira e esteja aberto para acreditar e confiar em algo positivo.

Estar atenta ao momento em que o familiar deseja ajuda da enfermeira.

Ajudar a ampliar a visão da situação concreta, estimulando sua vontade de encontrar conteúdos positivos e não estimular pensamentos negativistas.

Transmitir para o familiar com percepção de que a sua situação tem um significado, que nada na vida é em vão e que, naquela circunstância, tudo vai depender da maneira como ele se porta frente aos problemas.

Explicar que, por trás de um sofrimento, pode haver possibilidades de sentido.

Estimular a compreensão da importância da percepção e do amadurecimento interior através da situação experienciada.

Desmistificar concepções em relação à morte, à culpa, a rótulos e a pensamentos negativos.

Estar atenta às expressões de falta de força, vontade de viver e imobilidade para tomar decisões.

Despertar no familiar o desejo de ações, como possibilidade de execução para sentir-se útil. 
Continuação Quadro 3.

Lembrar ao familiar do paciente crítico as realizações agradáveis do passado, como um amor vivido, ou seja, a efetivação de uma lembrança plena de sentido.

Auxiliar o familiar a descobrir suas forças espirituais, para se auto-ajudar.

Identificar o momento em que o familiar percebe suas falhas, através de sentimentos de inutilidade, impotência e culpa para estimulá-lo a superá-los.

Ajudá-lo a despertar a consciência da sua responsabilidade para que ele possa apresentá-la através de uma atitude com sentido, frente à situação vivenciada por seu familiar na uti.

Ajudá-lo, naquela circunstância a tomar decisões positivas, não apenas reconhecendo o que é certo, mas querendo, no seu íntimo, agir da melhor maneira que lhe seja possível.

Estimular a reflexão, para apreensão do que percebe como sentido de vida.

Ajudar o familiar, incentivando à realização de uma atividade e/ou tarefa que preencha o vazio existencial.

Valorizar o estar-junto e cuidar do seu paciente, com essa atitude, a enfermeira estará liberando impulsos que ajudarão a enfrentar o medo.

Incentivar a prática religiosa, a fé e o desenvolvimento espiritual.

Estimular a oração, como meio de conexão com o seu deus interior e como possibilidade de reflexões, nas quais deus aparece como um parceiro em que se confia e com quem se dialoga, fazendo assim, emergir a confiança em si mesmo.

As atitudes de ajuda para implementar a estratégia de apoio, é direcionada pela compreensão da situação do familiar e ajuda ao lidar com o vazio existencial, também nome- ado de vazio interior, aparece na ausência de um conteúdo pessoal, uma vontade de sentido ou conteúdo de sentido frustrada com perda de sentido da existência (13).

\section{Quadro 4: Avaliação.}

\section{AVALIAÇÃO DAS ETAPAS}

A estratégias de ajuda de enfermagem são flexíveis, podendo ser alteradas a depender da situação particular vivenciada pelo enfermeiro com o familiar do paciente crítico.

Avaliar cada etapa durante o acompanhamento das relações do familiar do paciente crítico com o seu ente e com a equipe de enfermagem na UTI.

Reuniões com a equipe de enfermagem para discutir sobre as atitudes tomadas e refletir sobre a real positividade quanto à transformação da Tríade Trágica em otimismo trágico.

A avaliação do processo de ajuda interpessoal de enfermagem ao familiar do paciente crítico é necessária para que se aprecie a efetiva aplicabilidade ao familiar do paciente crítico com o intuito de tornar o momento de estar junto do seu ente na UTI pleno de sentido de vida e marcante por toda a sua existência. 


\section{CONCLUSÕES}

É importante que o enfermeiro e sua equipe se reúnam periodicamente para discutir as estratégias de cuidados utilizadas, as atitudes tomadas, as respostas das pessoas envolvidas nessa relação de ajuda e assim, refletir sobre o alcance das metas quanto à transformação da tríade trágica em otimismo trágico.

$\mathrm{O}$ apoio para o familiar do paciente crítico não consiste numa ajuda para simplesmente agradá-lo, mas para que ele possa transpor a condição de vivência na tríade trágica para a de otimismo trágico para a meta da resiliência. Dessa maneira, estimular-se-á o despertar da consciência pela apreensão dos valores expressos de maneira positiva, nas atitudes frente aos sentimentos de sofrimento, culpa e possibilidade de morte.

Conhecer os conteúdos de sentido, ao cuidar do familiar do paciente crítico, poderá auxiliar o enfermeiro a desenvolver suas ações, considerando esse familiar em suas dimensões humanísticas, existenciais e pessoais. Dos resultados da atenção de enfermagem ao familiar do paciente crítico podem emergir forças pessoais e espirituais que levam a resiliência.

Observa-se que a utilização de procedimentos não materiais, a exemplo do estímulo à profissão de fé evidencia a eficácia da terapêutica do paciente crítico e das forças que levam à expressão de conteúdos de sentido.

A ideia de usar recursos subjetivos e a afetividade intencionalmente só será possível pela motivação dos enfermeiros, no desejo de melhor cuidar, atentos ao guia, com disponibilidade por parte das direções institucionais nos recursos e ambiência para efetivação do processo.

\section{REFERÊNCIAS}

1. Torralba FR. Ética del cuidar: fundamentos, contextos y problemas. Madrid: Institut Borja de Bioética/Fundacion Mapfre Medicina; 2002. 286 p.

2. Waldow VR. Reflexões sobre Educação em Enfermagem: ênfase em um ensino centrado no cuidado. O Mundo da Saúde. Enfermagem [Internet]. 2009 [citado 15 out 2014]; 33(2): 182-188; PDF Disponível em: http://saocamilo-sp.br/pdf/ mundo_saude/67/182a188.pdf

3. Mendonça FMA, Jaldin MGM, Freitas IJS, Lima JVP, Dutra MB, Brito LMO. Revisitando o cuidado em saúde: revisão de literatura. Rev Pesq Saúde. [Internet]. 2012 [citado 15 out 2014]; 13(1): 55-59. Disponível em: http:// www.periodicoseletronicos.ufma.br/index.php/revistahuufma/article/view/1239/962

4. Waldow VR, Borges RF. Cuidar e humanizar: relações e significados. Acta Paul Enferm [Internet]. 2011. [citado 3 ago 2009]; 24(3); PDF Disponível em: http:// www.scielo.br/pdf/ape/v24n3/17.pdf.

5. Silva RS, Campos ERA, Pereira A. Caring for the patient in the process of dying at the Intensive Care Unit. Rev. Esc. Enferm. USP [Internet]. 2011 [citado $8 \mathrm{dez}$ 2013]; 45(3): 735-740. Disponível em: http://www.scielo.br/pdf/reeusp/v45n3/ en_v45n3a27.pdf

6. Ferreira PD, Mendes TN. Família em UTI: Importância do suporte psicológico diante da iminência de morte. Rev. SBPH [Internet]. 2013 [citado 3 nov 2014]; 16(1): 108-112. Disponível em: http:// pepsic.bvsalud.org/pdf/rsbph/v16n1/ v16n1a06.pdf 
7. Waldow VR, Fensterseifer LM. Saberes da enfermagem - a solidariedade como uma categoria essencial do cuidado. Esc. Anna Nery [Internet]. 2011 [citado 3 nov 2014]; 15(3): 629632. Disponível em: http://www.scielo. br/scielo.php?script=sci_arttext\&pi$\mathrm{d}=$ S1414-81452011000300027\&lng=en. DOI 10.1590/S1414-81452011000300027

8. Lützén K, Ewalds-Kvist B. Moral distress and its interconnection with moral sensitivity and moral resilience: viewed from the philosophy of Viktor E. Frankl. Bioethical Inquiry [Internet]. 2013. [citado 14 jun 2014]; 10: 31-324. Disponível em: http://pepsic.bvsalud.org/pdf/tp/v19n2/ v19n2a10.pdf

9. Frankl, VE. O sofrimento de uma vida sem sentido. São Paulo: Editora É Realizações; 2015. 128 p.

10. Lima AB, Santa Rosa DO. O sentido de vida do familiar do paciente crítico. Rev Esc Enferm USP [Internet]. 2008 [citado 08 dez 2013]; 42(3): 547-53. Disponível em: http://www.scielo.br/pdf/reeusp/ v42n3/v42n3a18.pdf

11. Horta, WA. Processo de Enfermagem. Rio de Janeiro: Guanabara Koogan; 2011. 112 p.

12. Frankl VE. Logoterapia e análise existencial. São Paulo: Forense; 2012. 350 p.

13. Frankl VE. A vontade de sentido: fundamentos e aplicações da logoterapia. São Paulo: Editora Paulus; 2011.224 p.

14. Frankl VE. O homem em busca de um sentido. Alfragide: Lua de papel; 2016. $160 \mathrm{p}$.
15. Martins JJ, Nascimento ERP, Geremias CK, Schneider DG, Schweitzer G, Mattioli Neto $\mathrm{H}$. $\mathrm{O}$ acolhimento à família na Unidade de Terapia Intensiva: conhecimento de uma equipe multiprofissional. Rev. Eletr. Enf. [Internet]. 2008 [citado 08 jun 2014]; 10(4): 1091-101. Disponível em: http://www.fen.ufg.br/revista/v10/ n4/v10n4a22.htm

16. Bicudo MAV. Pesquisa qualitativa segundo a visão fenomenológica. São Paulo: Cortez Editora; 2011. 152 p.

17. Bardin, L. Análise de conteúdo. São Paulo: Editora 70; 2011. 279 p.

18. Valadares GV, Paiva RS. Estudos sobre o cuidado à família do cliente hospitalizado: contribuições para enfermagem. Rev. Rene. Fortaleza. [Internet]. 2010 [citado 06 fev 2014]; 11(3): 180-188. Disponível em: http://www.revistarene.ufc.br/ vol11n3_pdf/a19v11n3.pdf

19. Vietta EP. Configuração triádica, humanista-existencial-personalista: uma abordagem teórico-metodológica de aplicação nas pesquisas de enfermagem psiquiátrica e saúde mental. Rev. LatinoAm Enfermagem [Internet]. 1995 [citado $09 \mathrm{dez} 2013$ ]; 03(1): 31-43. Disponível em: http://www. scielo.br/pdf/rlae/v3n1/v3n1a04.pdf

20. Silveira DR, Mahfoud M. Contribuições de Viktor Emil Frankl ao conceito de resiliência. Estudos de Psicologia I Campinas. [Internet]. 2008 [citado $31 \mathrm{dez}$. 2011]; I25(4): 567-576. Disponível em: http://www.scielo.br/pdf/estpsi/v25n4/ a11v25n4.pdf 